\title{
Impacto da nutrigenômica na prevenção de doenças crônicas: uma revisão
}

\author{
Impact of nutrigenomics in the Prevention of chronic diseases: a review \\ Impacto de la nutrigenómica en la prevención de enfermedades crónicas: una revisión
}

Recebido: 21/11/2021 | Revisado: 29/11/2021 | Aceito: 30/11/2021 | Publicado: 12/12/2021

\author{
Laíne de Almeida Sousa \\ ORCID: https://orcid.org/0000-0001-7232-4555 \\ Centro Universitário Santo Agostinho, Brasil \\ E-mail: lainesousa@gmail.com \\ Mikaelle Ravanna Oliveira Nascimento \\ ORCID: https://orcid.org/0000-0003-4200-2509 \\ Centro Universitário Santo Agostinho, Brasil \\ E-mail: mikaelleoliveira.nutri@gmail.com \\ Keila Cristiane Batista Bezerra \\ ORCID: https://orcid.org/0000-0002-0425-3596 \\ Centro Universitário Santo Agostinho, Brasil \\ E-mail: keilinhanut@gmail.com
}

\begin{abstract}
Resumo
Os estudos da nutrigenômica identificaram variantes genéticas que influenciam a ingestão e metabolismo de nutrientes específicos e preveem a variabilidade dos indivíduos em resposta a intervenções dietéticas. A metabolômica, revelou as impressões metabólicas do consumo de alimentos e nutrientes e descobriu novas vias metabólicas potencialmente modificadas pela dieta. Este trabalho teve como objetivo investigar as evidências científicas que comprovam a eficácia da nutrigenômica na alimentação e a prevenção de doenças crônicas não transmissíveis, bem como o impacto dos nutrientes na modulação da expressão gênica e prevenção destas patologias. Trata-se de uma revisão integrativa que permite combinar dados da literatura teórica que poderão direcionar a definição de conceitos, identificação, revisão e análise metodológica dos estudos sobre o tema. As evidências dos estudos de interação entre gene e nutriente com as DCNT's são relevantes não somente por identificarem a influência de um determinado gene, sobre um fenótipo em uma população com diferentes hábitos alimentares que podem potencialmente afetar esse fenótipo, mas também por avaliarem a resposta de uma intervenção dietética entre indivíduos com diferentes genótipos. O estudo relacionado a nutrigenômica mais especificamente com a genômica nutricional trás vários aspectos relevantes e de grande importância, possíveis benefícios para a melhora da qualidade de vida fazendo com que através dos compostos bioativos e nutrientes dos alimentos modulem a expressão gênica no genoma humano.
\end{abstract}

Palavras-chave: Nutrigenômica; Nutrientes; Prevenção de doenças crônicas.

\begin{abstract}
Nutrigenomics studies have identified genetic variants that influence specific nutrient intake and metabolism and predict the variability of individuals in response to dietary interventions. Metabolomics revealed the metabolic impressions of food and nutrient consumption and discovered new metabolic pathways potentially modified by diet. This work aimed to investigate the scientific evidence that proves the effectiveness of nutrigenomics in food and the prevention of chronic non-communicable diseases, as well as the impact of nutrients in the modulation of gene expression and prevention of these pathologies. It is an integrative review that allows combining data from the theoretical literature that can guide the definition of concepts, identification, review and methodological analysis of studies on the subject. Evidence from gene-nutrient interaction studies with CNCDs is relevant not only for identifying the influence of a particular gene on a phenotype in a population with different dietary habits that can potentially affect this phenotype, but also for evaluating the response of a dietary intervention among individuals with different genotypes. The study related to nutrigenomics, more specifically with nutritional genomics, brings several relevant and very important aspects, possible benefits for improving the quality of life, making it possible to modulate gene expression in the human genome through bioactive compounds and nutrients in food.
\end{abstract}

Keywords: Nutrigenomics; Nutrients; Chronic diseases Prevention.

\section{Resumen}

Los estudios de nutrigenómica han identificado variantes genéticas que influyen en la ingesta y el metabolismo de nutrientes específicos y predicen la variabilidad de los individuos en respuesta a las intervenciones dietéticas. La metabolómica reveló las impresiones metabólicas del consumo de alimentos y nutrientes y descubrió nuevas vías metabólicas potencialmente modificadas por la dieta. Este trabajo tuvo como objetivo investigar la evidencia científica que acredite la efectividad de la nutrigenómica en los alimentos y la prevención de enfermedades crónicas no transmisibles, así como el impacto de los nutrientes en la modulación de la expresión génica y prevención de estas 
patologías. Es una revisión integradora que permite combinar datos de la literatura teórica que pueden orientar la definición de conceptos, identificación, revisión y análisis metodológico de estudios sobre el tema. La evidencia de los estudios de interacción entre genes y nutrientes con las ECNT es relevante no solo para identificar la influencia de un gen en particular en un fenotipo en una población con diferentes hábitos alimenticios que potencialmente pueden afectar este fenotipo, sino también para evaluar la respuesta de una intervención dietética entre individuos. con diferentes genotipos. El estudio relacionado con la nutrigenómica, más concretamente con la genómica nutricional, trae varios aspectos relevantes y muy importantes, posibles beneficios para mejorar la calidad de vida, permitiendo modular la expresión génica en el genoma humano a través de compuestos bioactivos y nutrientes en los alimentos.

Palabras clave: Nutrigenómica; Nutrientes; Prevención de enfermedades crónicas.

\section{Introdução}

A Nutrigenômica, assim como outras ciências omicas, procuram definir e caracterizar as "assinaturas dietéticas" que refletem a ação dos nutrientes na estrutura e expressão do genoma e posteriormente os seus efeitos sobre a saúde. A Nutrigenômica tem buscado decifrar o impacto que os fatores nutricionais têm sobre a regulação e expressão de genes específicos, associando o potencial destes compostos no controle de doenças e os seus efeitos positivos a curto e longo prazo (Cahill et al., 2011).

O mapeamento genético realizado pelo Projeto Genoma Humano foi crucial para o fornecimento de novos conhecimentos sobre a influência dos nutrientes na expressão gênica em respostas ao processo metabólico na célula, influenciando na saúde do indivíduo. Logo, o sequenciamento do genoma humano ofereceu inúmeras vantagens para o estudo dos polimorfismos genéticos (Pavlidis; Patrinos; Katsila, 2015).

A genética propiciou grandes avanços na medicina como um todo. Permitiu análises mais amplas do genoma humano, da expressão genética, da variação genética individual e das interações entre os genes e o ambiente. Para a área da genômica nutricional, os estudos atualmente nos fornecem conhecimentos sobre como os nutrientes se comportam entre a saúde e a doença, como são as alterações da expressão e/ou estrutura dos genes do indivíduo, objetivando a procura para estabelecer o melhor tratamento nutricional de acordo com o genótipo individual (Buttendorf et al., 2018)..

Os estudos da nutrigenômica identificaram variantes genéticas que influenciam a ingestão e metabolismo de nutrientes específicos e preveem a variabilidade dos indivíduos em resposta a intervenções dietéticas. A metabolômica, revelou as impressões metabólicas do consumo de alimentos e nutrientes e descobriu novas vias metabólicas potencialmente modificadas pela dieta (Wang e $\mathrm{Hu}, 2018$ ).

De acordo com a World Health Organization (WHO) estimasse que, a cada ano, as DCNT matam cerca de 41 milhões de pessoas no mundo. Destas mortes, 15 milhões ocorrem com indivíduos da faixa de 30 a 69 anos e ainda, cerca de $85 \%$ das mortes prematuras ocorrem em países de baixa e média renda (Who, 2018).

De acordo com Valente et al. (2014), investigações vêm sendo desenvolvidas na tentativa de esclarecer como o meio, destacando o que se come, pode dar início às doenças. Sabendo que o genoma pode ser modulado por nutrientes e compostos bioativos dos alimentos, podem-se identificar indivíduos que respondam com menor eficiência à ingestão de alimentos e às vias metabólicas específicas. Tal colocação aponta para um caminho com enormes possibilidades de tratamento e/ou prevenção de DCNT, compreendendo a ligação entre o alimento e os aspectos genéticos de cada indivíduo (Coronado et al., 2011; Deus e Conceição, 2012).

O objetivo do estudo foi investigar as evidências científicas que comprovam a eficácia da nutrigenômica na alimentação e a prevenção de doenças crônicas não transmissíveis, bem como o impacto dos nutrientes na modulação da expressão gênica e prevenção destas patologias. 


\section{Metodologia}

Trata-se de uma revisão integrativa descritiva, qualitativa e exploratória da literatura que permite combinar dados da literatura teórica que poderão direcionar a definição de conceitos, identificação, revisão e análise metodológica dos estudos sobre o tema. A revisão integrativa da literatura é um método específico, que resume o passado da literatura empírica, ou teórica, para fornecer uma compreensão mais abrangente de um determinado fenómeno (Botelho et al., 2011).

As etapas do estudo irão incluir a definição da questão norteadora: de acordo com as recentes publicações sobre nutrigenômica e nutrigenética, os fatores dietéticos podem interferir na expressão gênica reduzindo o risco de desenvolvimento de doenças crônicas não transmissíveis?

A busca e seleção da literatura foram realizadas nas bases eletrônicas de dados, baseando-se em critérios de inclusão e exclusão e a apresentação dos resultados evidenciados na revisão, os artigos científicos serão retirados das bases de dados google acadêmico, SciELO (Scientific Electronic Library Online), PubMed (National Library of Medicine), BVS (Virtual Health Library), LILACS (Latin American and Caribbean Health Information). Foram utilizadas as seguintes palavras-chave “nutrigenômica", "nutrigenomics", “doenças crônicas”, “chronic diseases”, "nutrigenômica e obesidade", "nutrigenomics and obesity", "nutrigenômica e neoplasias", "nutrigenomics and neoplasms", "nutrigenômica e diabetes", "nutrigenomics and diabetes".

Os critérios de inclusão para esta revisão foram: artigos originais publicados na integra entre anos de 2011 a 2021 ; na língua portuguesa e inglesa que constituam relação existente entre nutrigenômica e DCNT (Doenças crônicas não transmissíveis) revistas, citações. Os critérios de exclusão envolveram artigos que não atenderam as etapas da metodologia do estudo, teses, dissertações, monografias, artigos originais publicados fora da temporalidade indicada e estudos que se repetiam nas bases eletrônicas.

Foram executadas pesquisas iniciais pelos resumos dos materiais que responderam aos descritores definidos, e foram classificados somente aqueles que expressam os fatores que se associam a nutrigenômica, em seguida ocorreu as análises das informações sobre as metodologias utilizadas, os resultados alcançados e as conclusões dos autores.

Logo após a leitura de todos os artigos selecionados foram aglomerados por temas e informações que irão dispor sobre os resultados, demonstrados em quadro para discussão dos dados, na configuração de artigo para a publicação em revista científica.

\section{Resultados e Discussão}

No Quadro 1 estão dispostos os 11 artigos publicados no período de 2011 a 2021 em ordem cronológica, selecionados de acordo com os critérios de inclusão anteriormente determinados levando em consideração as categorias: título, autores/ano, objetivo e resultados do estudo.

A análise das informações obtidas foi realizada com base em uma visão descritiva de modo que apresentasse as informações mais relevantes inclusas nos artigos. 
Quadro 1: Sinopse dos artigos incluídos nos resultados da revisão integrativa.

\begin{tabular}{|c|c|c|c|}
\hline TÍTULO & AUTORES / ANO & OBJETIVO & RESULTADOS \\
\hline $\begin{array}{l}\text { Um ensaio randomizado de } \\
\text { informação genética para } \\
\text { nutrição personalizada. }\end{array}$ & $\begin{array}{l}\text { Nielsen et al. } \\
\text { (2012) }\end{array}$ & $\begin{array}{l}\text { Comparar os efeitos de fornecer } \\
\text { aconselhamento dietético baseados em } \\
\text { genótipos com recomendações gerais } \\
\text { sobre resultados comportamentais. }\end{array}$ & $\begin{array}{l}\text { Os participantes desse estudo era homens e } \\
\text { mulheres com idades de } 20 \text { - } 35 \text { anos, os } \\
\text { participantes foram divididos no grupo de } \\
\text { intervenção (I) e grupo de controle } \\
\text { (C) onde cada grupo recebeu um aconselhamento } \\
\text { dietético individual baseado no seu genótipo. No } \\
\text { grupo de intervenção todos concordavam com as } \\
\text { recomendações dietéticas e seguiam a dieta } \\
\text { específica, e só apenas } 9 \% \text { se sentiram } \\
\text { desconfortáveis em realizar os testes genéticos. }\end{array}$ \\
\hline $\begin{array}{l}\text { Papel da variante de risco } \\
\text { TCF7L2 e ingestão de fibra } \\
\text { alimentar no incidente de } \\
\text { diabetes tipo } 2 .\end{array}$ & $\begin{array}{l}\text { Hindy et al. } \\
\text { (2012) }\end{array}$ & $\begin{array}{l}\text { Foi investigado se a interação entre a } \\
\text { ingestão alimentar de carboidratos, } \\
\text { gordura, proteína ou fibra e esta variante } \\
\text { afeta o risco de diabetes tipo } 2\end{array}$ & $\begin{array}{l}\text { O estudo foi realizado com } 24,799 \text { indivíduos não } \\
\text { diabéticos sendo } 13,571 \text { com genótipo CC, } 9,488 \\
\text { portadores do genótipo CT e } 1,740 \text { portadores do } \\
\text { genótipo TT, foi detectado que maior ingestão de } \\
\text { fibra foi associada à proteção contra diabetes tipo } 2 \\
\text { entre os portadores do genótipo CC, mas não entre } \\
\text { portadores do genótipo CT ou TT. }\end{array}$ \\
\hline $\begin{array}{l}\text { Polifenóis de azeite de oliva } \\
\text { aumentam a função de } \\
\text { lipoproteína de alta densidade } \\
\text { em humanos. Um ensaio clínico } \\
\text { randomizado }\end{array}$ & $\begin{array}{l}\text { Hernáez et al. } \\
\text { (2014) }\end{array}$ & $\begin{array}{l}\text { O objetivo do estudo foi avaliar se o } \\
\text { consumo de azeite de oliva rico em } \\
\text { polifenóis poderia aumentar a função } \\
\text { principal do HDL, sua capacidade de } \\
\text { efluxo (captura de colesterol e os } \\
\text { principais tipos de células envolvidas são } \\
\text { os macrófagos sob o endotélio dos vasos } \\
\text { sanguíneos) e algumas de suas } \\
\text { propriedades relacionadas a qualidade, } \\
\text { conteúdo, tamanho e composição. }\end{array}$ & $\begin{array}{c}\text { Foi realizado um ensaio randomizado cruzado com } \\
47 \text { voluntários saudáveis do sexo masculino, onde } \\
\text { os integrantes consumiram } 25 \mathrm{ml} \text { de azeite de oliva } \\
\text { cru pobre em polifenóis }(2,7 \mathrm{mg} / \mathrm{kg} \text { ) e azeite rico em } \\
\text { polifenóis ( } 366 \mathrm{mg} / \mathrm{kg} \text { ) durante três semanas, } \\
\text { precedido por uma pausa de duas semanas, } \\
\text { aprimorou-se a capacidade de captura do colesterol } \\
\text { pela lipoproteína HDL, posteriormente a } \\
\text { intervenção de oferecer azeite rico em polifenóis } \\
\text { versus pobre em polifenóis. Os níveis de HDL } \\
\text { eram superiores apor a intervenção com azeite rico } \\
\text { em polifenóis em comparação com a intervenção } \\
\text { pobre em polifenóis. Os autores relataram que o } \\
\text { óleo de oliveira rico em polifenóis é apto a } \\
\text { aumentar a expressão de genes que estabeleçam } \\
\text { relação ao metabolismo e a função de HDL. }\end{array}$ \\
\hline $\begin{array}{l}\text { Frutas secas ricas em polifenóis } \\
\text { e fibras com chá verde atenuam } \\
\text { a glicose sanguínea pós- } \\
\text { prandial derivada do amido e } \\
\text { insulina: uma intervenção } \\
\text { randomizada, controlada, cega, } \\
\text { cruzada. }\end{array}$ & $\begin{array}{l}\text { Silavwe et al. } \\
\text { (2016) }\end{array}$ & $\begin{array}{l}\text { O objetivo do estudo foi testar se o PFRF } \\
\text { (Alimentos ricos em polifenóis e fibras) } \\
\text { poderia atenuar a glicose sanguínea pós- } \\
\text { prandial em voluntários saudáveis quando } \\
\text { adicionado a uma fonte de carboidrato } \\
\text { (amido no pão). }\end{array}$ & $\begin{array}{l}\text { Os testes foram realizados com } 16 \text { voluntários } \\
\text { saudáveis, que participaram em jejum de } 4 \text { visitas, } \\
2 \text { visitas de controle (pão, água, açúcares } \\
\text { balanceados) e } 2 \text { visitas de teste ( dose única e dose } \\
\text { dupla de alimentos ricos em polifenóis e fibras } \\
\text { como pão, água e PFRF), foram coletadas amostras } \\
\text { de sangue dos voluntários em jejum e logo após o } \\
\text { consumo dos alimentos foi coletado o sangue } 8 \\
\text { vezes de } 15 \text { em } 15 \text { minutos. Os componentes PFRF } \\
\text { foram testados para o potencial inibidor de } \alpha \text { - } \\
\text { amilase e } \alpha \text { - glucosidase in vitro. }\end{array}$ \\
\hline $\begin{array}{l}\text { Comparação de ferramentas de } \\
\text { interface de tecnologia } \\
\text { nutrigenômica para } \\
\text { consumidores e profissionais de } \\
\text { Saúde: protocolo para um } \\
\text { estudo de métodos mistos. }\end{array}$ & $\begin{array}{l}\text { Littlejohn et al. } \\
\qquad \text { (2018) }\end{array}$ & $\begin{array}{l}\text { O objetivo principal deste estudo foi } \\
\text { investigar se a recomendação dietética } \\
\text { personalizada com base em testes } \\
\text { genéticos fornecidos por um médico leva a } \\
\text { melhoria na alimentação e resultados de } \\
\text { saúde em comparação com uma } \\
\text { abordagem não assistida por profissionais } \\
\text { (Abordagem autodirigida ao consumidor). }\end{array}$ & $\begin{array}{l}\text { Dos } 478 \text { Indivíduos demonstraram interesse, } 180 \\
\text { foram convidados e concluíram a seleção de } \\
\text { elegibilidade do questionário, } 73 \text { dos } 180 \\
\text { convidados foram classificados como elegíveis, dos } \\
73 \text { indivíduos } 58 \text { finalizaram o questionário de } \\
\text { saúde e registro alimentar, desses } 58 \text { indivíduos } 3 \\
\text { integrantes foram descartados por não preencherem } \\
\text { todo o formulário. A amostra final foi de } 55 \\
\text { pessoas em sua maioria mulheres casadas com } \\
\text { ensino superior completo. O alto nível de interesse } \\
\text { nessa pesquisa e a taxa de retenção extremamente } \\
\text { alta demonstraram que existe um grande interesse } \\
\text { nessa área da nutrigenômica, contudo há } \\
\text { necessidade de mais estudos para que haja o } \\
\text { aprofundamento de conhecimento. }\end{array}$ \\
\hline $\begin{array}{l}\text { O efeito da ingestão habitual de } \\
\text { gordura, polimorfismo IL6, e } \\
\text { diferentes estratégias de dieta } \\
\text { sobre inflamação em mulheres } \\
\text { na pós-menopausa com }\end{array}$ & $\begin{array}{c}\text { Chmurzynska et al. } \\
\text { (2019) }\end{array}$ & $\begin{array}{l}\text { Os objetivos foram analisar o efeito da } \\
\text { ingestão de gorduras sobre biomarcadores } \\
\text { de inflamação, incluindo a transcrição dos } \\
\text { genes TNF e IL6, e concentrações } \\
\text { sanguíneas de IL6 e TNF alfa, analisarem } \\
\text { o efeito do polimorfismo IL6 nos } \\
\text { parâmetros antropométricos e }\end{array}$ & $\begin{array}{l}\text { Os níveis de transcrição de IL6 e TNF em PBMCs } \\
\text { antes do DI não foram afetados pela ingestão de } \\
\text { energia de base de gordura, ingestão de gordura } \\
\text { total, PUFA ou ingestão de MUFA. No entanto, } \\
\text { menor ingestão de SFA foi associada a } \\
\text { uma transcrição de } T N F \text { mais de } 500 \text { vezes } \\
\text { menor. Especificamente, os valores medianos } \\
\text { do TNFos níveis de transcrição relativos foram } \\
0,000576 \text { e } 0,000001 \text {, nos grupos SFA baixo e alto, } \\
\text { respectivamente. A quantidade de ingestão de } \\
\text { energia da linha de base da gordura afetou as }\end{array}$ \\
\hline
\end{tabular}




\begin{tabular}{|c|c|c|c|}
\hline obesidade central & & $\begin{array}{c}\text { biomarcadores de inflamação da } \\
\text { população alvo antes da intervenção } \\
\text { dietética e avaliar como intervenções } \\
\text { dietéticas que diferem em gorduras, } \\
\text { carboidratos, MUFAs e teor de fibra } \\
\text { alimentar podem afetar esses parâmetros } \\
\text { na população alvo. }\end{array}$ & $\begin{array}{c}\text { concentrações iniciais de IL6. Especificamente, a } \\
\text { alta ingestão de energia da gordura foi associada a } \\
\text { níveis mais elevados de IL6. Além disso, a alta } \\
\text { ingestão de energia da proteína resultou em maiores } \\
\text { concentrações de TNF } \alpha \text { no sangue. A ingestão de } \\
\text { SFA, MUFA ou PUFA não afetou os níveis de IL6 } \\
\text { ou TNF } \alpha .\end{array}$ \\
\hline $\begin{array}{l}\text { Associações específicas de } \\
\text { ancestralidade da variante do } \\
\text { gene FTO e síndrome } \\
\text { metabólica: um estudo } \\
\text { longitudinal ARIC. }\end{array}$ & $\begin{array}{l}\text { Hardy et al. } \\
\text { (2020) }\end{array}$ & $\begin{array}{c}\text { Teve como objetivo mostrar que os níveis } \\
\text { mais altos de atividade física podem } \\
\text { diminuir o efeito deletério de rs } 9939609 \\
\text { em índice de massa corporal (IMC) mais } \\
\text { alto. }\end{array}$ & $\begin{array}{c}\text { Foi feito um estudo utilizando um banco de dados } \\
\text { de genótipos e fenótipos para } 10.358 \text { participantes, } \\
\text { com idades diferentes entre } 45 \text { anos a } 64 \text { anos, em } \\
\text { afro-americanos e brancos, onde foi feito um } \\
\text { levantamento que o alto nível de triglicerídeos } \\
\text { elevados foram entre os portadores afro-americano } \\
\text { de alto risco de AA. }\end{array}$ \\
\hline $\begin{array}{l}\text { Preditores da intenção das } \\
\text { partes interessadas de adotar } \\
\text { nutrigenômica. }\end{array}$ & $\begin{array}{c}\text { Mustapa et al. } \\
.(2020)\end{array}$ & $\begin{array}{l}\text { Este estudo tem como objetivo analisar as } \\
\text { intenções das partes } \\
\text { interessadas da Malásia em adotar a } \\
\text { nutrigenômica e determinar os fatores que } \\
\text { influenciam suas intenções. }\end{array}$ & $\begin{array}{l}\text { A nutrigenômica e os testes- genéticos obteve uma } \\
\text { aceitação relevante sendo importante preditores os } \\
\text { benefícios percebidos, os riscos encontrados não } \\
\text { foram significativos para que houvesse uma } \\
\text { rejeição a abordagem da nutrigenômica, no } \\
\text { processo de tomada de decisão eles se concentram } \\
\text { mais nos aspectos benéficos. }\end{array}$ \\
\hline $\begin{array}{l}\text { Melhoria da mudança dietética } \\
\text { a longo prazo e aderência em } \\
\text { um guia orientado por } \\
\text { nutrigenômica } \\
\text { intervenção de estilo de vida } \\
\text { em comparação com um } \\
\text { estilo de vida baseado na } \\
\text { população (GLB / DPP) } \\
\text { intervenção para controle de } \\
\text { peso: resultados do ensaio } \\
\text { randomizados } \\
\text { controlado. }\end{array}$ & $\begin{array}{l}\text { Horne et al. } \\
\qquad(2020)\end{array}$ & $\begin{array}{c}\text { O objetivo deste estudo foi determinar } \\
\text { se uma intervenção de estilo de vida } \\
\text { guiada por um programa de nutrigenômica } \\
\text { poderia ser usado para motivar uma maior } \\
\text { adesão a dieta e mudança na ingestão } \\
\text { alimentar de curto prazo, moderado e } \\
\text { longo prazo em comparação com o } \\
\text { controle de peso baseado na população do } \\
\text { padrão ouro } \\
\text { intervenção (Group Lifestyle Balance } \\
\text { (GLB) / Diabetes } \\
\text { Programa de Prevenção (DPP). }\end{array}$ & $\begin{array}{l}\text { O estudo foi realizado por uma população } \\
\text { feminina, de meia idade, com muita motivação, } \\
\text { cheia de atitudes e com obesidade, todas com } \\
\text { mesmo propósito mudar sua ingestão alimentar, } \\
\text { comer de forma mais saudável, onde houve uma } \\
\text { divisão de grupo GLB + NGx, todas tiveram um } \\
\text { acompanhamento de } 3 \text { meses que avaliaram uma } \\
\text { mudança no comportamento e no teste genético das } \\
\text { participantes, analisaram que a nutrigenômica pode } \\
\text { ajudar na prevenção da obesidade na ingestão e } \\
\text { orientação nutricional adequada. }\end{array}$ \\
\hline $\begin{array}{l}\text { Interações de índices } \\
\text { antropométricos, polimorfismo } \\
\text { rs9939609 gene FTO, câncer de } \\
\text { mama: um estudo-controle. }\end{array}$ & $\begin{array}{c}\text { Doaei et al. } \\
(2021)\end{array}$ & $\begin{array}{c}\text { Avaliar as interações entre o polimorfismo } \\
\text { rs9939609 do gene FTO, índices } \\
\text { antropométricos e risco de BC em } \\
\text { mulheres iranianas. }\end{array}$ & $\begin{array}{l}\text { Foi realizado um estudo com } 540 \text { mulheres adultas, } \\
\text { divididas em dois grupos, } 180 \text { mulheres com câncer } \\
\text { (grupo caso) e } 360 \text { mulheres saudáveis ( grupo } \\
\text { controle ) com o IMC médio de } 29 \text { e } 27 \\
\text { respectivamente, foi feita uma análise a fim de } \\
\text { investigar os efeitos da massa corporal, índice } \\
\text { sobre a relação entre o gene FTO e o câncer de } \\
\text { mama somente no indivíduos com sobrepeso de } \\
\text { ambos os grupos. }\end{array}$ \\
\hline $\begin{array}{l}\text { Associação entre o SNP FTO } \\
\text { rs9939609 e a síndrome } \\
\text { metabólica em crianças } \\
\text { chilenas. }\end{array}$ & $\begin{array}{l}\text { Luque et al. } \\
\qquad(2021)\end{array}$ & $\begin{array}{l}\text { O objetivo deste estudo foi investigar a } \\
\text { associação entre o rs } 9939609 \text { no gene } \\
\text { FTO e a síndrome metabólica e avaliar os } \\
\text { componentes da síndrome metabólica } \\
\text { nesta mesma população infantil chilena. }\end{array}$ & $\begin{array}{c}\text { Os resultados mostraram que a RI (resistência a } \\
\text { insulina) aumenta significativamente entre os } \\
\text { diferentes genótipos, sendo maior no AA } \\
\text { (homozigotos). Essa tendência leva a um aumento } \\
\text { da insulinemia como mecanismo compensatório } \\
\text { que previne a hiperglicemia em crianças. Por esse } \\
\text { motivo, a glicemia basal elevada é o componente } \\
\text { menos prevalente da SM }(9,5 \%) \text {. Apesar disso, esse } \\
\text { critério esteve mais presente entre os portadores } \\
\text { dos genótipos TA e AA }\end{array}$ \\
\hline
\end{tabular}

Fonte: Autores (2021).

Observou-se no estudo de Nielsen et al. (2012), que os indivíduos estão interessados na nutrigenômica e relatam que as recomendações dietéticas baseadas na genética são mais úteis do que as recomendações dietéticas gerais. Embora exista preocupação sobre o potencial da informação genética para induzir ansiedade em alguns indivíduos, muito poucos participantes no grupo de intervenção concordaram que se sentiram desconfortáveis ao aprender sobre sua informação genética. Em vez disso, 96\% dos participantes que receberam suas informações genéticas concordaram que gostaram de aprender sobre suas informações genéticas e recomendações dietéticas. Essa descoberta sugere que fornecer esse tipo de informação provavelmente não induz ansiedade e que os jovens podem abraçar uma nova era de nutrição personalizada que pode surgir por meio do avanço da genômica personalizada. As recomendações dietéticas baseadas no genótipo foram relatadas como mais compreensíveis do que as recomendações dietéticas gerais e também foram relatadas como mais úteis. Os participantes relataram que não se sentiriam 
desconfortáveis em aprender sobre suas próprias informações genéticas. Consistente com isso, os participantes do grupo de intervenção não expressaram desconforto em aprender sobre sua genética e foram mais propensos a relatar prazer em aprender sobre as recomendações dietéticas que receberam, bem como um desejo maior de saber mais sobre as recomendações. Testes genéticos diretos ao consumidor baseados em nutrição personalizada podem, portanto, ser mais valiosos do que aqueles baseados exclusivamente em previsões de risco de doenças.

Conforme o estudo de Littlejohn et al. (2018), foi identificado que o alto nível de interesse expresso e a taxa de retenção de participantes indicam que os consumidores são receptivos a abordagens de nutrição personalizadas. A ciência emergente da nutrigenômica combinada com intervenções nutricionais personalizadas são os meios ideais de fornecer conselhos dietéticos para a população em geral, subgrupos genéticos e indivíduos. No entanto, é necessária uma demanda por produtos de interface digitais mais sofisticados e fáceis de usar que integrem as informações fenotípicas de uma pessoa com seu estado nutricional atual (por exemplo, antropometria, atividade física), ingestão alimentar atual e informações sobre nutrição do genótipo.

Os resultados de Mustapa et al. (2020), mostram que os benefícios percebidos foram os preditores mais importantes da intenção de um indivíduo de adotar a nutrigenômica, enquanto os riscos percebidos foram apenas fracamente relacionados à intenção. Embora as partes interessadas da Malásia pareçam ter avaliado os benefícios e riscos da nutrigenômica, esses resultados sugerem que, durante o processo de tomada de decisão, eles tendem a se concentrar mais nos aspectos benéficos.

Horne et al. (2020), fornecem evidências convincentes de que a adição de nutrigenômica a um dos programas mais eficazes de controle de peso de saúde pública e prevenção de diabetes pode ajudar a motivar e otimizar diferenças clinicamente significativas de longo prazo na ingestão nutricional e adesão às diretrizes dietéticas.

Nos resultados de Hindy et al. (2012), indicam que o a ingestão de fibras dietética pode modificar a associação entre TCF7L2 rs7903146 e a incidência de diabetes tipo 2, e que maior ingestão de fibras pode estar associada a proteção contra diabetes tipo 2 apenas entre portadores de alelos de risco.

Silavwe et al. (2016), afirmou que o consumo de alimentos ricos em polifenóis e fibras (PFRF) juntamente com o pão resultou em uma redução altamente significativa da AUC da glicose, dependente da dose, bem como uma atenuação associada da insulina. A redução observada na glicemia pós-prandial e na insulina pode desempenhar um papel importante no controle e redução do risco de diabetes tipo 2 , pois a hiperglicemia é um fator de risco para o desenvolvimento de resistência à insulina, IGT e, consequentemente, diabetes tipo 2. Polifenóis e fibras presentes nas frutas, juntamente com uma xícara de chá verde, têm um efeito acentuado na redução da glicose e insulina pós-prandial quando consumidos junto com um alimento amiláceo (pão), devido à inibição de diferentes estágios da digestão do amido.

Luque et al. (2021) mostrou que a RI (resistência a insulina) aumenta significativamente entre os diferentes genótipos, sendo maior no AA. Em termos de distribuição entre os genótipos, todos os critérios de SM foram significativamente mais prevalentes em AA, exceto em hiper-TG. Cada cópia do alelo A representou um aumento linear significativo nas razões de prevalência dos critérios de obesidade abdominal e alteração de HDL-C, nossos resultados mostram que para cada alelo de risco (A), há um aumento significativo da quantidade de tecido adiposo e da obesidade abdominal medida pela CC.

No estudo de Hardy et al. (2020) os resultados mostram que a variante rs9939609 do FTO teve pequenas contribuições para aumentar o risco de SM em brancos nos modelos de efeitos principais. Entre os brancos, altos níveis de atividade física foram protetores contra o efeito deletério do FTO rs9939609 na SM, independentemente de eles terem IMC normal, estarem acima do peso ou serem obesos.

Considerando a pesquisa feita por Chmurzynska et al. (2019) ressaltou-se que antes da intervenção dietética, a menor ingestão habitual de SFA estava associada à menor transcrição do TNF, mas não às concentrações sanguíneas de TNFa. Embora nenhuma associação entre a ingestão de gordura ou ácido graxo (AF) e a transcrição de IL6 em PBMCs tenha sido detectada, as 
concentrações de IL6 no sangue foram maiores em mulheres na pós-menopausa, cujo percentual de energia da gordura era maior.

Na pesquisa de Hernáez et al. (2014), determinou que a propriedade funcional do HDL foi amplamente testada em várias linhagens celulares de macrófagos e foi inversamente relacionada ao desenvolvimento precoce da aterosclerose e ao alto risco de sofrer um evento coronariano. nesse mesmo estudo, constatou o consumo de polifenóis do azeite de oliva por 3 semanas induziu um aumento significativo da principal função biológica do HDL e aumentou a capacidade de efluxo de colesterol do HDL dos voluntários em um modelo fisiológico de macrófagos derivados de monócitos THP-1. Um efeito semelhante foi descrito após o consumo de azeite extra virgem, e após o consumo de nozes ou um tratamento com pioglitazona. Os polifenóis do azeite de oliva também induziram alterações nas propriedades bioquímicas da lipoproteína, o que pode ter contribuído para o aumento da função HDL.

Doaei et al. (2021) não encontrou associação significativa entre o BC (câncer de mama) e o alelo de risco do polimorfismo rs9939609 do FTO nos participantes com diferentes IMC. Outro achado importante deste estudo foi a frequência significativamente maior do alelo de risco do polimorfismo rs9939609 em pessoas com excesso de peso com câncer de mama do que em pessoas saudáveis com excesso de peso.

\section{Considerações Finais}

Contudo, este estudo mostra que o conhecimento da nutrigenômica é essencial na área da saúde por seu grande potencial de benefícios que por ela podem ser oferecidos, onde a intervenção dietética auxilia na pré-disposição de doenças crônicas, podendo assim, ajudar na contribuição genética de cada indivíduo na nutrição personalizada.

Neste estudo também revela que as doenças crônicas estão interligadas ao perfil genético e as respostas metabólicas de acordo as suas necessidades nutricionais, assim a nutrigenômica tem contribuído para o conhecimento das intervenções gene nutrientes e quais substâncias irão afetar um gene que possivelmente possa vir desencadear ou reprimir a expressão do polimorfismo para uma determinada doença.

Portanto conclui-se que a nutrigenômica pode ser uma possível solução para a diminuição do índice de doenças crônicas não- transmissíveis, uma vez que os nutrientes alteram os processos do DNA, expressão genética e o metabolismo. Por fim ainda são necessários mais estudos para melhor entendimento e adoção da nutrigenômica no âmbito clínico.

\section{Referências}

Basadre, M., M. (2019). Nutrigenômica e Nutrigenética: O Futuro da Nutrição. Revista Ciência e Saúde Integrando conhecimento, pág. ag. 15 -16.

Cintra, F. F., Pissinati, J. T., Gasques, L. S., \& Arrieira, R. L. (2020). Influência da nutrição na expressão de genes relacionados à obesidade. Arquivos de Ciências da Saúde da UNIPAR, 24(2).

Castro, E. C., \& GINI, L. P. (2021). Nutrigenética e Nutrigenômica no tratamento e prevenção de doenças crônicas não transmissíveis.

Coronado, M., Vega e León, S., Gutiérrez, R., Pérez, J., \& Peláez, K. (2011). Nutrigenética aplicada: dieta personalizada y formación académica para la práctica profesional. Revista chilena de nutrición, 38 (4), 492-500.

da Silva, S. A. L., \& Pimenta, R. S. (2019). A nutrigenômica como método de prevenção e tratamento de doenças. desafios Revista Interdisciplinar da Universidade Federal do Tocantins, 6(3), 3-10.

Deus, K. J., \& Conceição, R. S. D. (2012). Diabetes mellitus tipo 2-a relação genética-nutrientes. Nutrire Rev. Soc. Bras. Aliment. Nutr, $199-214$.

de Sousa, L. M. M., Marques-Vieira, C. M. A., Severino, S. S. P., \& Antunes, A. V. (2017). A metodologia de revisão integrativa da literatura em enfermagem. $N^{\circ} 21$ Série 2-Novembro 2017, 17.

Fernandes, DP, Coutinho, VEA, de Brito Medeiros, L., \& Pereira, NLV (2020). Nutrientes e compostos bioativos na modulação epigenética associada à prevenção e combate ao câncer. Research, Society and Development, 9 (4), e114942914-e114942914.

Hardy, D. S., Garvin, J. T., Mersha, T. B., \& Racette, S. B. (2020). Ancestry specific associations of FTO gene variant and metabolic syndrome: A longitudinal ARIC study. Medicine, 99(6). 
Research, Society and Development, v. 10, n. 16, e245101623681, 2021

(CC BY 4.0) | ISSN 2525-3409 | DOI: http://dx.doi.org/10.33448/rsd-v10i16.23681

Hindy, G., Sonestedt, E., Ericson, U., Jing, X. J., Zhou, Y., Hansson, O., ... \& Orho-Melander, M. (2012). Role of TCF7L2 risk variant and dietary fibre intake on incident type 2 diabetes. Diabetologia, 55(10), 2646-2654.

Horne, J., et al. (2020). Melhoria da mudança dietética de longo prazo e adesão em uma intervenção de estilo de vida guiada por nutrigenômica em comparação com uma intervenção de estilo de vida baseada na população (GLB / DPP) para controle de peso: resultados do ensaio clínico randomizado NOW. BMJ Nutrition, Prevention \& Health, 3 (1), 49.

Hernáez, Á., Fernández-Castillejo, S., Farràs, M., Catalán, Ú., Subirana, I., Montes, R., ... \& Fitó, M. (2014). Os polifenóis do azeite de oliva aumentam a função da lipoproteína de alta densidade em humanos: um ensaio clínico randomizado. Arteriosclerose, trombose e biologia vascular, 34 (9), $2115-2119$.

Littlejohn, P., Cop, I., Brown, E., Afroze, R., \& Davison, KM (2018). Comparação de ferramentas de interface de tecnologia nutrigenômica para consumidores e profissionais de saúde: protocolo para um estudo de métodos mistos. Protocolos de pesquisa JMIR, 7 (6), e115.

Mustapa, M. A. C., Amin, L., \& Frewer, L. J. (2020). Predictors of stakeholders' intention to adopt nutrigenomics. Genes \& nutrition, 15(1), 1-15.

Molina-Luque, R., Ulloa, N., Romero-Saldaña, M., Zilic, M., Gleisner, A., Lanuza, F., \& Molina-Recio, G. (2021). Associação entre o FTO SNP rs9939609 e a Síndrome Metabólica em Crianças Chilenas. Nutrients, 13 (6), 2014.

Nielsen, D. E., \& El-Sohemy, A. (2012). A randomized trial of genetic information for personalized nutrition. Genes \& nutrition, 7(4), 559-566.

Nyambe-Silavwe, H., \& Williamson, G. (2016). Frutas secas ricas em polifenóis e fibras com chá verde atenuam a glicose no sangue pós-prandial derivada do amido e a insulina: uma intervenção randomizada, controlada, simples-cega e cruzada. British Journal of Nutrition, 116 (3), 443-450.

Organização Mundial da Saúde. (2018). Perfis de países com doenças não transmissíveis 2018.

Saraiva, A. V. C., de Azevedo Marques, N., da Cunha Leal, P., \& Machado, R. R. P. (2020). Nutrigenética e nutrigenômica: conceitos e abordagens esquemáticas para o processo ensino-aprendizagem deste saber. Brazilian Journal of Development, 6(9), 69737-69751.

Santos, 1. f. d., \& Albuquerque, e. p. a. (2019). nutrigenômica, nutrigenética e suas aplicações.

Schmidt, L., Soder, T. F., \& Benetti, F. (2019). Nutrigenômica como ferramenta preventiva de doenças crônicas não transmissíveis. Arquivos de Ciências da Saúde da UNIPAR, 23(2).

Sharma, P., \& Dwivedi, S. (2017). Nutrigenômica e nutrigenética: uma nova visão na prevenção e cura de doenças.

Sousa, L. M. M. S., Marques-Vieira, C. M. A., Severino, S. S., \& Antunes, A. V. (2017). Metodologia de revisão integrativa da literatura em enfermagem.

Valente, M. A. S., de Albuquerque Barbosa, M. C., Rodrigues, C. V., Vieira, P. A. F., \& de Oliveira Barbosa, M. (2014). Nutrigenômica/nutrigenética na elucidação das doenças crônicas. HU Revista, $40(3$ e 4).

Vieira, J. A. de T et al. (2015). A nutrigenômica na prevenção e combate as células neoplásicas. Revista Fafibe Online, p. 140 - 153. 